\title{
Interactive Multimodal Metadiscourse in COVID 19 Campaign Posters by Ministry of Health, Kenya
}

\author{
Khadohi Bonface Isalambo, Dr. Odhiambo Kenneth
}

${ }^{1}$ Department of Languages Literature and Culture, Maasai Mara University, Kenya

\begin{abstract}
The purpose of this study is to examine the interactive multimodal metadiscourse features of campaign posters developed exclusively by Kenya's Ministry of Health (MoH) or collaboratively with religious groups and development partners. The objectives of the study were to establish the generic structure, categories, frequencies and functions of interactive textual metadiscourse and visual resources. Using a mixed research design employing qualitative and quantitative research approaches, the study analyzed a corpus of 25 posters on six thematic areas including social stigma, immunity, signs and symptoms, handwashing, immunity, mental health. The frame work of analysis is partly drawn from Hyland's interpersonal model of metadiscourse (2005) and Kress (2010) and Kress and Van Leewun (2001, 2002, 2006) on visual interactive resources. The findings revealed presence of evidentials, code glosses and frame markers in the textual metadiscourse used by the poster designers. Evidentials were the most frequent used textual metadiscourse markers followed by code glosses and frame markers. On use of interactive visual resources, the research established use of information value, framing, connective devices and fonts to supplement the textual interactive metadiscourse devices to guide the readers. The results expand our knowledge on multimodality communication in respect to guiding readers when engaging in multimodal public health communication.
\end{abstract}

Keywords-interactive multimodal metadiscourse, interactive metadiscourse, visual interactive resources, campaign posters.

\section{INTRODUCTION}

A poster is a temporary promotion of an idea, product or event put up in public space for mass consumption (Lippert, 2017). It is classified as multimodal because it contains both textual and graphic elements, although they may be wholly graphical or textual. Research on posters can be categorized into four areas specifically, entertainment, commercial, political and educational posters performing the key functions of informing, persuading and entertainment (Holloway, 2014). The poster is a condensed and specialized genre. This research focuses on educational posters and more specifically public health posters which seek to inform and educate the general public on the global pandemic, COVID19.

The emergence of the global pandemic, COVID-19 has created a specialized form of discourse manifest in the way government communicates to the public. In Kenya, the Ministry of Health has used posters among other communication initiatives as a preventive strategy to control the pandemic and deal with the risk factors associated with the pandemic. In its attempts to effect behaviour change in the members of the public, the ministry in collaboration with religious groups and civil society has created campaign posters with several messages on pandemic. This study seeks to establish how the campaign poster designers guide the readers to COVID-19 information using interactive linguistic resources- metadiscourse and visual grammar- despite their physical absence on the Ministry's website.

Metadiscourse is a term used in discourse analysis based on a view of writing or speaking as a social and communicative engagement and reveals the way writers project themselves into their discourse to signal their attitudes and commitments to matters in the text (Hyland, 2005). This linguistic concept of metadiscourse enables writers to create considerate texts because they take into accounts the reader's needs and expectations. A considerate text presupposes two levels of 
operation by the text creators: the level of the text (discourse) and the level of metatext (metadiscourse). In the former, the propositional content is expanded while the latter the readers are assisted to organize, classify, interpret, evaluate and react to the propositional content (Vande Kopple, 1985).

Hyland's metadiscourse (2005) interpersonal model, based on a functional approach, recognizes two dimensions of interaction: interactive and interactional. The interactive resources guide the reader through the text while the interactional resources involve the reader in the text. The two levels have five sub-categories each that have specific functions with varying lexical realizations. The five interactive resources-focus of this study-are as follows: transitions, frame markers, endophoric markers, evidentials and code glosses. The table below shows the interactive resources sub-categories.

Table 1: Hyland (2005 p. 49) Metadiscourse model-Interactive resources

\begin{tabular}{|cl|l|l|}
\hline \multicolumn{2}{|l|}{ Category } & Function & Examples \\
\hline Interactive & Help to guide the reader through the text & Resources \\
\hline 1) & Transitions & Express relations between main clauses & in addition; but; thus; and \\
\hline 2) & Frame markers & Refer to discourse acts, sequences or stages & finally; to conclude; my purpose is \\
\hline 3) & Endophoric markers & Refer to information to other parts of the text & noted above; see Fig, in section 2 \\
\hline 4) & Evidentials & Refer to information from other texts & according to X; Z states \\
\hline 5) & Code glosses & Elaborate propositional meanings & $\begin{array}{l}\text { Namely; e.g; such as; in other } \\
\text { words. }\end{array}$ \\
\hline
\end{tabular}

Several linguistic scholars have decried the over emphasis of discourse analysis primarily on its language and its forms (O'Hollaran, 2004; Kress and Van Leewun, 2006, Li and Jung, 2015) whose consequence has been ignoring of semiotic resources such as images, space and architecture. This paper seeks a balanced and comprehensive approach to discourse analysis that gives emphasis to both textual and visual forms by infusing Kress and Van Leewun's (2006) visual semiotic theory for poster analysis. The two proponents of visual grammar argue that images, like language, have grammar structures that can be analyzed for meaning.

Table 2: Visual interactive resources (drawn from Kress/van Leewun, 1996, 2006, and Kress, 2010).

\begin{tabular}{|l|l|l|}
\hline Interactive Resources & Achieved through & Function \\
\hline Information Value & Left- Right & Organize the layout of information of a poster \\
& Top-Bottom & \\
Centre-Margin & \\
& Triptych & \\
\hline \multirow{3}{*}{ Framing } & Frame lines & Distinguish sections of a text \\
& Color contrast & \\
\hline Connective Elements & Emply space between element & \\
& - Vectors & Connect ideas and parts of visual and textual \\
& - Repetition of color & discourse \\
& $-\quad$ Alignment & \\
\hline
\end{tabular}

Similar to Hyland's (2005) metadiscourse model, Kress and Van Leewun's (2006) categorize the visual elements as interactive or interactional depending on their communicative functions. Interactive visual elements guide reader in comprehension of multimodal text while interactional visual elements are used to engage and involve readers in multimodal text. The interactive elements- focus of this study- are as follows: information value, framing, connective element, graphs and fonts. Table 2 captures the visual resources sub categories. 


\begin{tabular}{|c|c|c|}
\hline Graphic Elements & $\begin{array}{ll}\text { - } & \text { Conversion processes } \\
\text { - } & \text { Taxonomies } \\
\text { - } & \text { Flowcharts } \\
\text { - } & \text { Networks } \\
\text { - } & \text { Tables } \\
\text { - } & \text { Figures (pie charts, graphs) } \\
\text { - } & \text { Pictures } \\
\text { - } & \text { Schematic analytical } \\
& \text { Pictures }\end{array}$ & $\begin{array}{l}\text { Clarify and organize data for the viewer, aiding the } \\
\text { immediate retention of information }\end{array}$ \\
\hline Fonts & $\begin{array}{ll}\text { - } & \text { Size } \\
\text { - } & \text { Colour } \\
\text { - } & \text { Type }\end{array}$ & $\begin{array}{l}\text { Enhance legibility; Help clarify parts of discourse, } \\
\text { highlighting the most important parts of the text; } \\
\text { Clarifies the organization of text }\end{array}$ \\
\hline
\end{tabular}

Despite the huge potential of multimodal metadiscourse analysis on reader guidance and analysis in the construction of meaning, researchers have not utilized its communication potential in health communication. This study explores how interpersonal communication is signaled linguistically through the combined framework- interactive metadiscourse and visual grammar resources- in campaign posters developed collaboratively between the $\mathrm{MoH}$, religious groups and development partners using Hyland's (2005) metadiscourse model and Kress and Van Leewun's (2006) visual grammar model to guide their readers in construction of meaning.

The study is guided by the following objectives: first, identify and categorize the interactive multimodal metadiscourse features in campaign posters; second, establish the frequency of interactive multimodal metadiscourse features in campaign posters; and finally, explain the functions of multimodal metadiscourse in campaign posters.

\section{LITERATURE REVIEW}

Some researchers have analyzed campaign posters by partially employing Kress and Van Leewun (2006) visual grammar model. Oyebode and Onuabonah (2013)undertakes a multimodal discourse analysis of health communication by exploring the communicative acts in creation of HIV/AIDS posters with focus on people living with HIV/AIDS and their relatives and friends using six posters obtained from two state hospitals in south-western Nigeria. The findings revealed presence of communicative acts of instructing, advising, beckoning, encouraging, warning, encouraging, warning and informing. Although the study's focus is not COVID-19, it employs Kress and Van Leewun framework and therefore provides insights on how to analyze the campaign posters.

ISSN: 2456-7620
With regard to the global pandemic, COVID-19 there has been attempts to analyze multimodal metadiscourse using Kress and Leewun visual grammar on the COVID-19 pandemic discourse. Yuigin and Rui (2020) analyzed the discourses of words and images of collected during the COVID-19 pandemic in China based on the visual grammar of Kress and Leewun. The findings reveal that the meanings of words and images of COVID-19 in China are constructed through the three aspects of interactive, representative and compositional meaning. The authors explain that the images and words work together to achieve the overall interpretation of the text. The current study borrows visual grammar approach in combination with underutilized Hyland's interpersonal model of metadiscourse.

Some researchers have pursued multimodality on a purely interactive aspect with focus on social media. Baraza, Khasanda and Nyandoro (2020)performed a discursive analysis of the interactive meaning in COVID-19 containment discourses in social media using Critical Discourse Analysis (CDA) and Multimodal Discourse Analysis (MDA) within Systemic Functional Linguistics (SFL) as its theoretical bases. The purpose of the study was to analyze interactive meaning is facilitated in linguistic and visual mode in 28 texts sampled from the Internet and WhatsApp groups. The findings revealed several thematic family issues ranging from poverty, strained couple relationships, spouse cheating, spousal phone swooping, couple dominance and power struggles among other issues. However, the current study is on campaign posters.

The potential of metadiscourse expansion to the visual realm to help readers navigate texts has been explored by various researchers. Kumpf (2000) explains how metadiscourse acan utilized by authors as a design criterion when considering the needs and expectations of readers of technical documents. Kumpf's work was applied in the reader orientation's work 
produced by the sugar industry (Bonaventura, 2009) and inserts of the Illustrated Basic Dictionary of American English Dictionary where visual metadiscourse was used to organize content and engage readers (Fechine and Pontes, 2012). D' Angelo (2016) explores how academic conference posters use visual as well as textual resources to communicate interactive and interactional meanings.

D'Angelo (2018) further explores multimodal metadiscourse and visual grammar by conducting a cross disciplinary research on the academic poster genre which revealed discipline specific features concerning textual interactive and interactional metadiscourse resources and visual interactive resources. The framework analysis for the study in anchored on Hyland's (2005) Metadiscourse model, Kress (2010) and Kress and Van Leewun (2006) applied to the disciplines of Applied Linguistics, Medicine, Economics, Biology and Geography. Biology posters contained the largest amount of textual interactive resources followed by Economics and Geography posters. Comparatively, applied linguistics and Medical posters used less textual interactive resources.

A majority of visual metadiscourse works on posters have been on academic conference posters (D'Angelo, 2010, 2016,2018 ) and visual grammar on previous pandemics more specifically, HIV discourse (Bok, 2013; Oyebode and Onuabonah 2013). This study seeks to fill a critical economical mode of multimodal communication, public health posters, given scanty attention by researchers.
Although D'Angelo's framework focus is academic posters, this study seeks to employ the framework to analyze public health posters and more specifically, COVID- 19 campaign posters. The communication of public health information is crucial in the containment of contagious diseases. The framework will help understand how the poster designers guide the readers using interactive metadiscursive textual and visual resources in reading information on COVID-19.

\section{METHODOLOGY}

This study adopts a mixed methods research design, which combines both qualitative and quantitative elements of research. The rationale for the choice of the design is based on the research objectives- frequencies, categories and functions of metadiscourse. Shorten and Smith (2017) explain that a mixed method design is appropriate for answering research questions that neither qualitative or quantitative methods can answer alone.

The corpus for this research consists of 25 campaign posters developed with $\mathrm{MoH}$ exclusively and collaboratively with religious institutions and development partners. The disciplinary scope is the following thematic areas on COVID-19 messages are as follows: signs and symptoms, social stigma, mental health, how to maintain a strong immunity, wearing of masks, protecting the family, social distancing, handwashing recommendations for children, messages to parents, caregivers and guardians.

Table 3: Total number of words contained in each sub-corpus

\begin{tabular}{|l|l|l|l|}
\hline Poster Category & Collaboration & Total & No. of Tokens \\
\hline Social stigma & $\mathrm{MoH}$ & 4 & 173 \\
\hline $\begin{array}{l}\text { Message to parents, caregivers and } \\
\text { guardians }\end{array}$ & $\mathrm{MoH}$ & 1 & 60 \\
\hline $\begin{array}{l}\text { Mental health messages for health care } \\
\text { providers/ Stress management }\end{array}$ & $\mathrm{MoH}$ & 3 & 306 \\
\hline Recommendations for children & $\mathrm{MoH}$ & 2 & 300 \\
\hline COVID 19 signs and symptoms & $\mathrm{MoH}$, Interreligious Council \& Norwegian Church Aid & 2 & 91 \\
\hline Maintaining strong immunity & $\begin{array}{l}\text { MoH, Feed Children, World Vision, Red Cross, } \\
\text { UNICEF, Nutrition International, Feed the Children }\end{array}$ & 4 & 408 \\
\hline Mask & MoH \& Green String Network & 1 & 61 \\
\hline Observing social distancing & MoH, Interreligious Council \& Norwegian Church Aid & 3 & 246 \\
\hline Protecting family & MoH, Interreligious Council \& Norwegian Church Aid & 2 & 164 \\
\hline Handwashing & MoH, Interreligious Council \& Norwegian Church Aid & 2 & 181 \\
\hline Counselling & Red Cross \& MoH & 1 & 35 \\
\hline Total & & $\mathbf{2 5}$ & $\mathbf{2 , 0 2 5}$ \\
\hline
\end{tabular}

To analyse the corpus, Hyland (2005) interpersonal model and Kress and Van Leewun (2006) visual grammar was used

ISSN: 2456-7620

https://dx.doi.org/10.22161/ijels.55.38 to identify the interpersonal resources- both interactive and interactional metadiscursive devices. The posters, which 
were in PDF format, were converted into text to develop a corpus of 2,025 tokens. The concordance software Wordsmith Tool 4 developed by Scott (1997) was used for corpus compilation, development and analysis. The Concord was applied to the corpus to establish the distribution and frequency of metadiscourse. A qualitative functional interpretation of the quantitative patterns was done. The interactive visual resources were identified through a qualitative analysis and each poster considered having binary features for example +F-F- frame lines, no frame lines to indicate presence or absence of interactive visual resources.

\section{RESULTS AND DISCUSSION}

Guided by the research objectives and analysis of $\mathrm{MoH}$ Corpus both manually and using concordance software,
Oxford Wordsmith Tool 4, this section discusses the results of interactional metadiscourse and visual semiotic and grammar resources analyses with focus on types, frequencies and types within the e-posters.

\subsection{Interactive Metadiscourse}

The micro searches conducted on the $\mathrm{MoH}$ posters corpus revealed the presence of three traditional metadiscursive features (frame markers, code glosses and evidentials). Interactive metadiscourse is because of the writer's assessment of the assumed reader's comprehension capacities, understandings of related texts and used for interpretive guidance (Hyland, 2005). The distribution of interactive metadiscursive features is as follows:

Table 4: Total number of interactive resources

\begin{tabular}{|l|l|l|l|}
\hline Category & $\begin{array}{l}\text { \% of Interactional } \\
\text { metadiscourse }\end{array}$ & Raw frequency & $\begin{array}{l}\text { Frequency per 100 } \\
\text { words }\end{array}$ \\
\hline Frame markers & & 20 & 1.0 \\
\hline Code glosses & & 35 & 1.75 \\
\hline Evidentials & & 76 & 3.8 \\
\hline Transition markers & - & - & - \\
\hline Endophoric markers & - & - & - \\
\hline & 100 & 137 & \\
\hline
\end{tabular}

The most frequent interactive metadiscursive feature as captured in the above table are evidentials, followed by code glosses. Frame markers are the least used metadiscursive features. The absence of transition markers and endophoric markers can be attributed to the multimodal nature of posters. These features have been replaced by other visual interactive features.

\subsubsection{Evidentials}

These metadiscursive devices are representations of an idea from another source, which guide the reader's interpretation and establish an authorial command of the subject (Hyland, 2005). Table 4 indicates 3.8 evidentials per a thousand words, which is higher than Hyland's study of academic textbooks, which had 1.7 evidentials per a thousand words. The high frequency of evidentials in comparison with other metadiscursive devices can be attributed to efforts by the Ministry to convince the public of inclusivity of their representatives- the religious groups. Thus, attributions to sources with positive evaluations- religious groups and development partners- are used as endorse the Ministry's message to bridge the trust deficit of the general public with the government. In the posters, the logos and names of institutions involved implicitly establish an authorial command of the COVID-19 message.

Evidentials are used through attribution to stakeholder approach to the COVID-19 pandemic through logos placed at header and footer of the poster. For example, in Figure 1, the header has Government of Kenya and while the footer captures Feed Children, World Vision, UNICEF, Kenya Red Cross and Nutritional International on message to the general public on how to improve immunity within the COVID-19 context. The same applies to other messages - which have the Government of Kenya on the header and Inter-religious Council of Kenya, African Council of Religious Leaders and Norwegian Church Aid on the footer. 


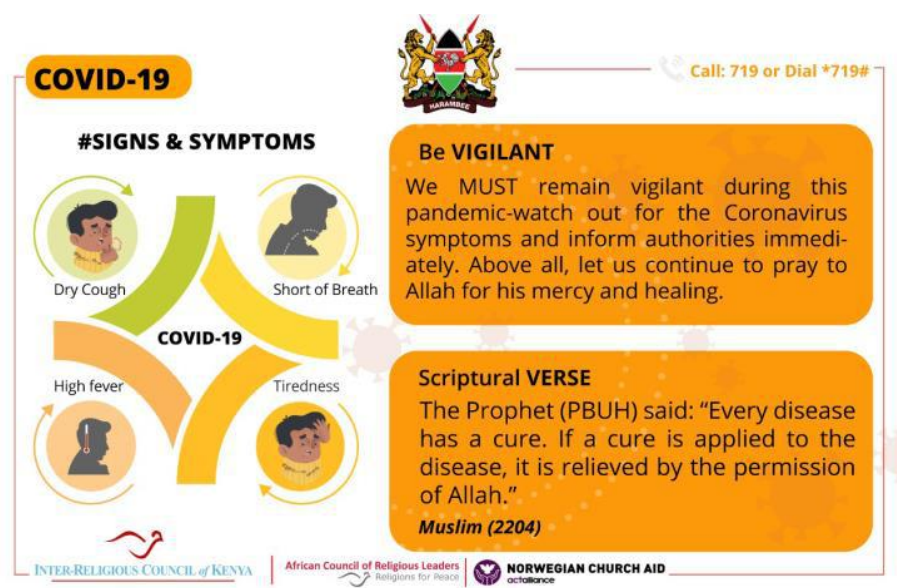

Fig.1: Poster on signs and symptoms

The logos from the Ministry of Health, religious groups and development partners perform a metadiscursive role by constantly reminding and assuring the readers the source of information. Michael (2008) explains that evidentials are the elements that indicate source of information upon which an utterance is based. In this case, the COVID signs and symptoms the message source is what appears in the header and footer.

\subsubsection{Code glosses}

These metadiscursive features supply additional information in discourse by rephrasing, explaining or elaborating what has been said, to ensure that the reader is able to recover the writer's intended meaning (Hyland, 2005). Table 4 reveals a frequency of 1.75 code glosses per thousand words slightly higher than to Gonzalez (2005) corpus of virtual bank's web sites at 1.5 code glosses per a thousand words. Generally, the code glosses are used in explaining and rephrasing scientific terminology and jargon which all the readers may not be conversant with.

In Figure 2, the poster designers are aware that they are addressing the general public who might not be conversant with the scientific terminology such as "processed foods" hence use of parenthesis (added sugar, fat, salt) to ensure readers comprehend the message in terms of what to avoid in building their immunity in the context of COVID-19.

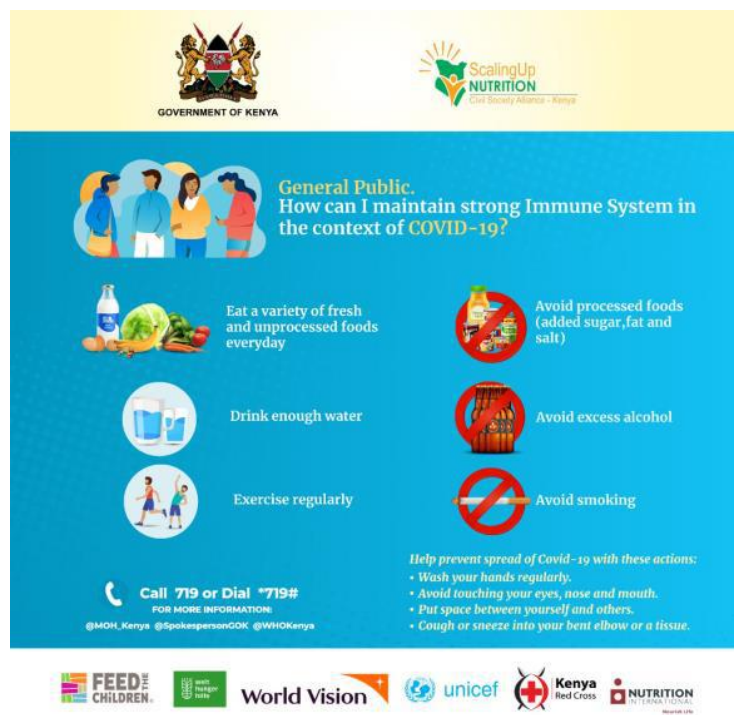

Fig.2: poster for general public on immunity

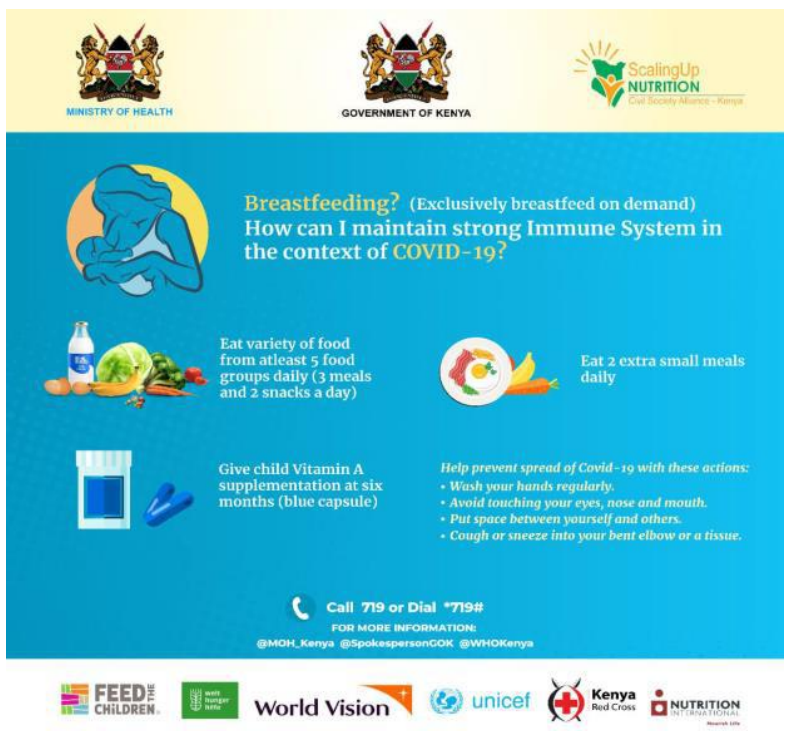

Fig.3: poster for breastfeeding mothers on immunity

Similarly, in Figure 3 above, the use of code glosses has been used to aid reader understand

Vitamin B supplements by placing its appearance in brackets (blue capsules) and also expounding on meaning of five food groups daily in parenthesis ( 3 meals and 2 snacks a day).

\subsubsection{Frame markers}

These metadiscourse features signal text boundaries or elements of schematic text structure (Hyland, 2005). The devices function to sequence, label, predict and shift arguments making the discourse clear to the public reading 
COVID-19 campaign posters. As indicated in Table 4, the frequency of frame markers is 1 per a thousand words which is less than Hyland's metadiscourse studies on textbooks $(1998,2000)$ which had 3.8 per a thousand words and Khadohi (2009) on corporate websites with 3 per a thousand words.

In Figure 4, the frame marker has been used to announce goals of public health communication through the demonstrative pronoun these actions. The following campaign poster developed by the Ministry of Health uses numbers $(01,02,03,04,05)$ to indicate to the reader the order in which the text should be read in terms of the vulnerable groups. The members with underlying medical conditions are considered most vulnerable and elderly placed at the end of the list.

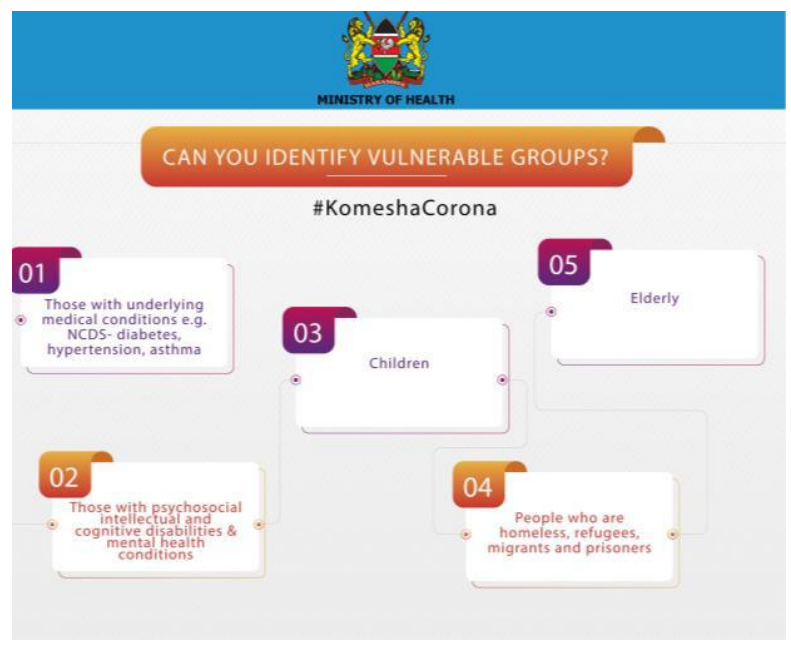

Fig. 4: poster on vulnerable groups

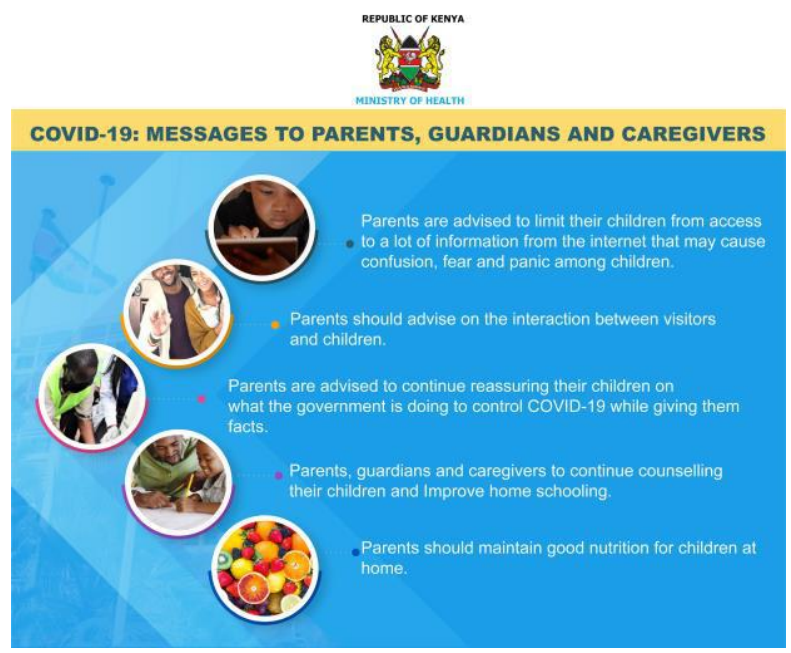

Fig.5: poster for parents, guardians and caregivers
Apart from numbering, Figure 5 uses of bulletins and dots are used as metadiscursive features to draw to the attention of readers the preventive issues meant to instill behavioural change. These elements indicate to campaign readers the order in which the text should be read.

\subsection{Interactive visual metadiscourse}

The visual interactive resources used to complement the textual interactive metadiscourse are framing, fonts, connective elements and information value as illustrated in Table 5. Graphs which are extensively applied in academic posters to guide readers are sparingly used in campaign posters. The presence and absence of visual interactive resources is represented by the binary features as captured by information value left-right + and Tryptich-, the former implies presence while the latter absence of the resource.

Table 5: Interactive visual resources

\begin{tabular}{|c|c|c|}
\hline $\begin{array}{l}\text { Interactive } \\
\text { Resources }\end{array}$ & Subtype & \\
\hline \multirow[t]{5}{*}{ Information Value } & Left- Right & + \\
\hline & Top- Bottom & + \\
\hline & Centre- Margin & - \\
\hline & Tryptich & - \\
\hline & & 2 \\
\hline \multirow[t]{5}{*}{ Framing } & Frame lines & + \\
\hline & Discontinuities of colours & - \\
\hline & Discontinuities of shapes & + \\
\hline & $\begin{array}{l}\text { Empty space between } \\
\text { elements }\end{array}$ & + \\
\hline & & 3 \\
\hline \multirow[t]{5}{*}{ Connective elements } & Vectors & + \\
\hline & Repetition of shapes & + \\
\hline & Repetition of colours & + \\
\hline & Alignment & - \\
\hline & & 3 \\
\hline \multirow[t]{6}{*}{ Graphs } & Conversion process & - \\
\hline & Charts & - \\
\hline & Taxonomies & + \\
\hline & Flowcharts & - \\
\hline & Networks & - \\
\hline & & 1 \\
\hline \multirow[t]{4}{*}{ Font } & Colour & + \\
\hline & Size & + \\
\hline & Type & + \\
\hline & & 3 \\
\hline Total & & 12 \\
\hline
\end{tabular}


In the campaign posters analyzed using Kress and Van Leewun (2006) framework on interactive resources, several interactive resources are used to make the posters clear. There were 12 categories of visual interactive resources used by the poster designers out of the possible 20 .

\section{2.1 Information Value}

Information value is created through placement of elements. The posters arrangement whether done unilaterally or collaboratively determines placement of elements. For example, all the posters developed by Ministry of Health as represented by Figure 6 follow the top-bottom order.

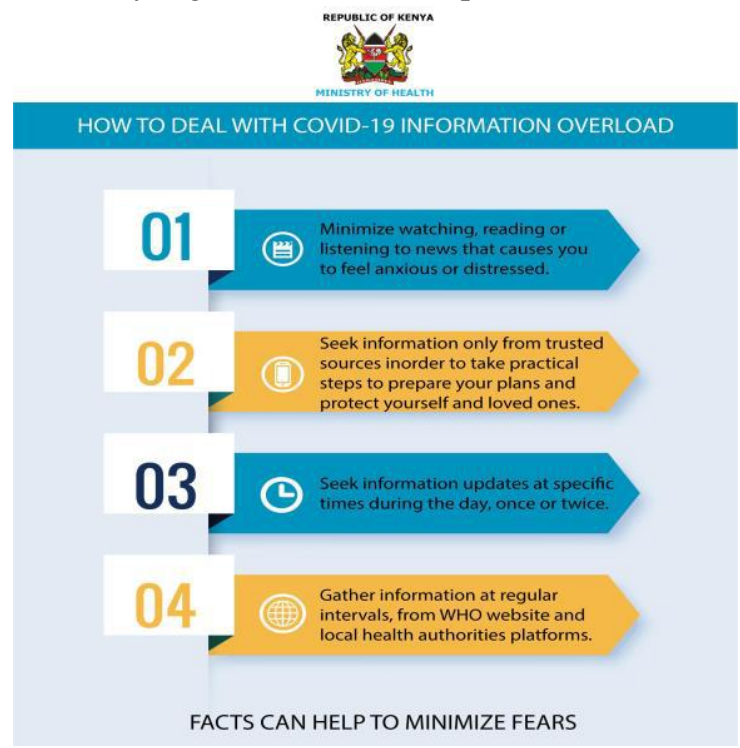

Fig. 6: Posters on COVID-19 information overload

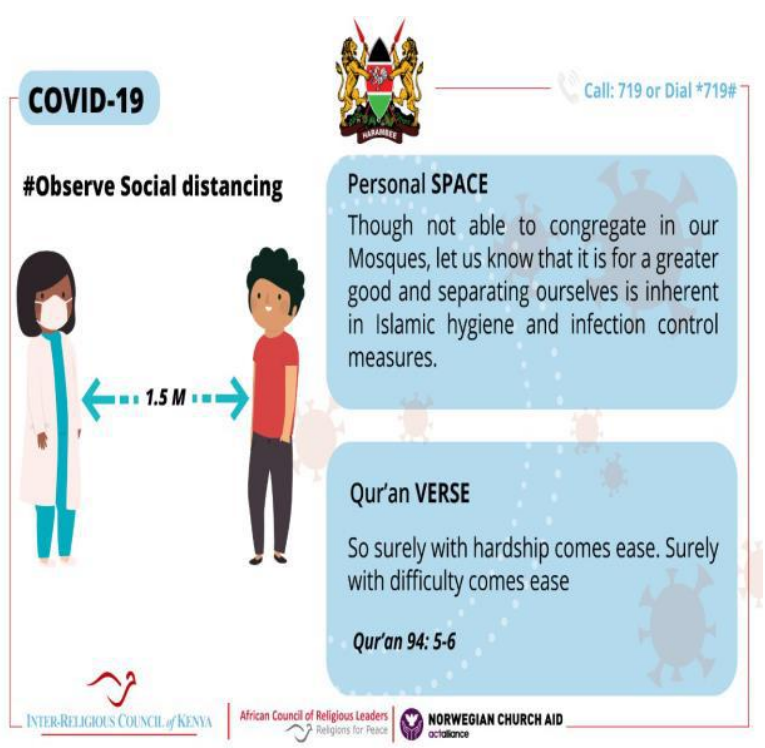

Fig. 7: poster on social distancing
The posters developed collaboratively as represented by Figure 7 between the $\mathrm{MoH}$ and religious institutions follow the left to right order with two vertical columns. The designers of the posters have divided it into two vertical columns suggesting the reader move his gaze from left to right. Symbolically, the arrangement captures shared space with each party using its allotted space to communicate its message. On the left side of the poster, the Ministry communicates visually on social distancing while the religious groups represented by Muslims qualify the message with a religious interpretation on personal space.

\subsubsection{Framing and connective devices}

Framing plays an interactive metadiscursive role through use of frame lines, colour contrast and empty spaces between texts to distinguish sections of a text. Figure 8 communicates COVID-19 health messages for health care providers. The poster designers use colour contrast- blue and yellow- to guide readers to the propositional content-various coping strategies. Frames are captured in circular and rectangular shapes, the former bearing textual advisory while the latter visual images illustrating the advisories.

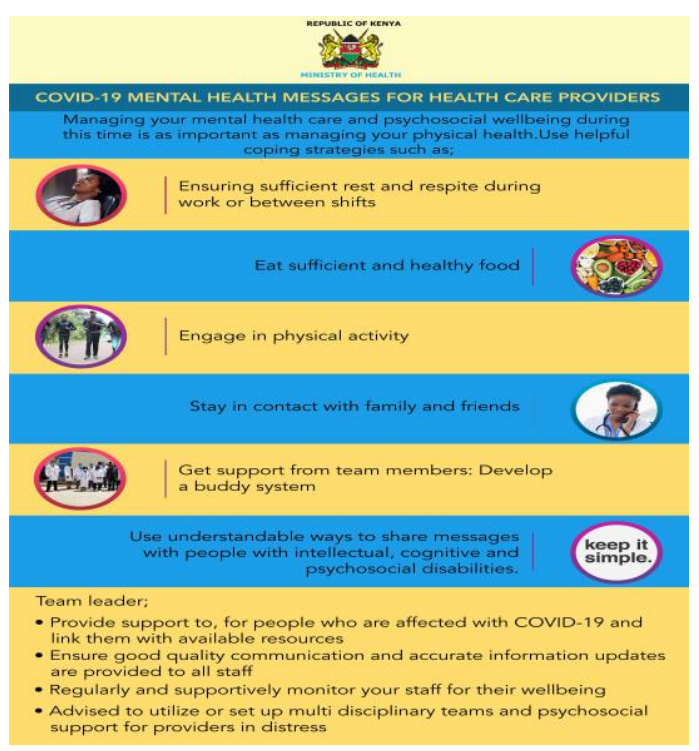

Fig.8: poster on mental health 


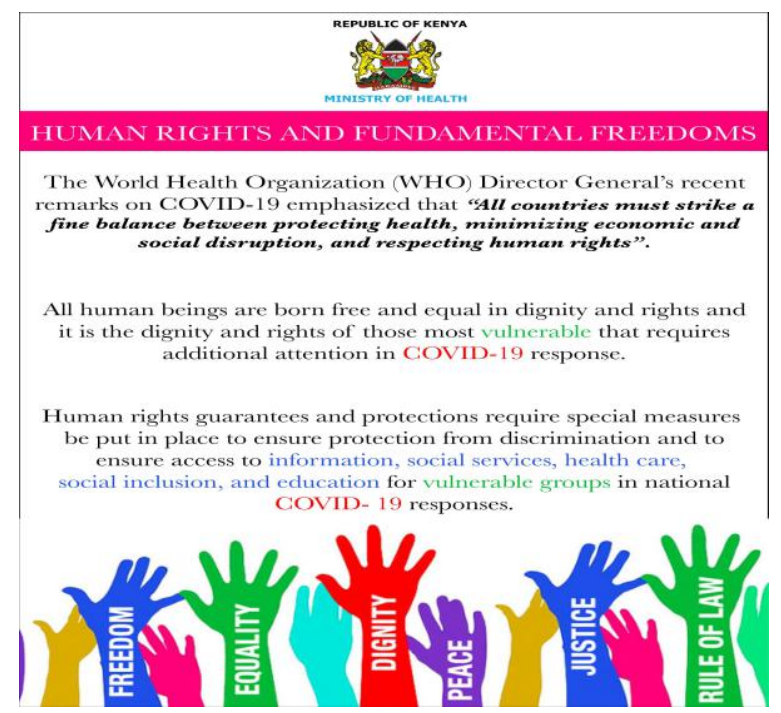

Fig.9: poster on human rights

The empty spaces play a metadiscursive role in Figure 9 by separating the three messages and focusing our attention to each: first WHO general message on protection of rights within the context of COVID-19; second, the right to equality and dignity; third emphasis on protection of rights and access to information, health care, education for the vulnerable groups during the COVID-19 period.

The poster designers have also used connectives in the campaign posters to guide the reader to show the connection between various sections of textual or visual texts (Kress and Van Leewun, 2006). Figure 9 uses the hand as a symbol of the various rights captured in different colours- freedom, equality, dignity, peace and rule of law. The colour red representing danger is used for COVID-19 while green the target for the pandemic- vulnerable groups. The connective devices in Figures 8 are achieved through repetition of colour and shapes, the blue and yellow colours meant to help readers focus afresh on each coping strategy.

Other connective devices used are vectors achieved through geometrical symbolism and arrows. Figure 10 which communicates to the general public on social stigma presents the message in four boxes with different colours; the first box introduces us to the topic of social stigma through a vector relation by employing straight arrows arranged in form of a taxonomy to direct the reader to message- paying attention to language; the third and fourth vector presents variants of circular arrows reminding readers on personal responsibility in communicating COVID-19 messages to avoid social stigma.

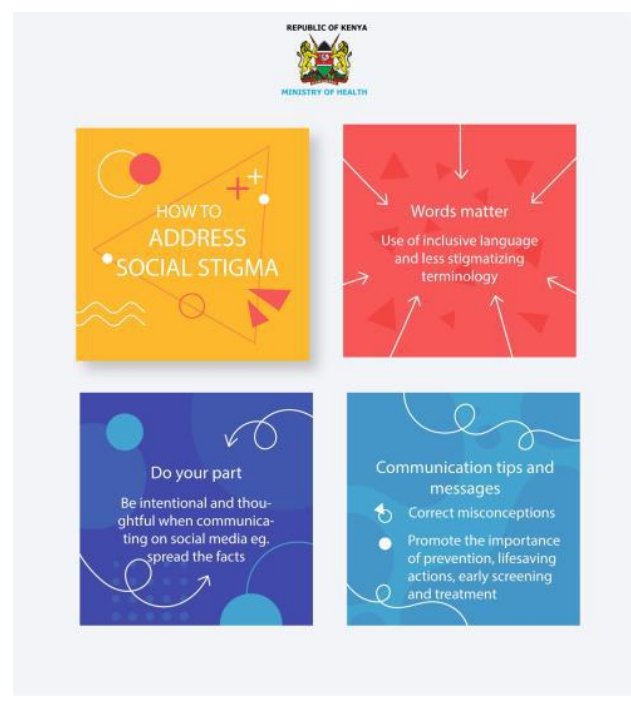

Fig.10: poster on social stigma

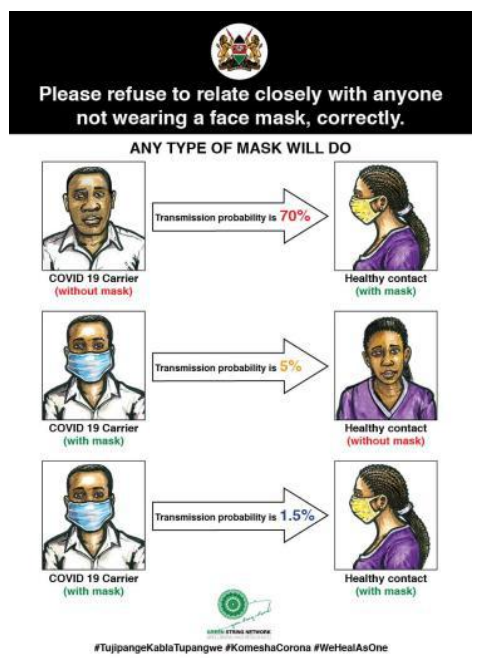

Fig.11: poster on social distancing

Figure 11 has a vectorial relation through three unidirectional arrows indicating a transactional action connecting the actorCOVID-19 carrier and potential healthy contact with arrows carrying information on transmission probability.

\section{CONCLUSION}

This paper has presented a quantitative and qualitative research on the types, frequencies and functions of interactive textual and visual metadiscourse in campaign posters developed singularly by Ministry of Health or collaboratively with religious institutions and development partners. The study reveals presence of evidentials, code glosses and frame markers in the textual metadiscourse used by the poster designers and absence of transitions and frame 
markers. The research further establishes use of information value, framing and connective devices that supplement interactive textual metadiscourse to guide the readers.

\section{REFERENCES}

[1] Baraza M.N, Khasanda, V. 1 \& Nyandoro, G. (2020). A discursive analysis of the interactive meaning in COVID 19 containment discursive discourses in social media: perspectives on family relationships. International Journal of English Literature and Social Sciences (IJELS). Retrieved from

http://journal-repository.com/index.php/ijels/article/view/2318

[2] Bok, S.H. (2013). A multimodal analysis of selected national love Life HIV/AIDS prevention campaign texts. (Master's thesis, University of the Western Cape)

[3] Bonaventura, P. (2009) Sing like no one can hear you, dance like no one can see you but write like everyone will read you. 31st Annual Australian Society of Sugar Cane Technologists Conference, ASSCT 2009 pp. 345-356

[4] D'Angelo, L. (2016). Academic poster presentations: Mapping the genre, in Gotti, M. (ed.), Academic identity traits. A corpus-based investigation, Peter Lang, Bern, pp. 263-282.

[5] D'Angelo, L. (2018) Academic Posters -A textual and visual metadiscourse analysis. Bern: Peter Lang.

[6] Fechine, L. \&amp; Pontes, A.L. (2012). The visual metadiscourse of the inserts of an English

[7] dictionary. Calidoscopio10 (3), pp. 294-300

[8] Gonzalenz, R. (2005). Textual metadiscourse in commercial websites, Iberica-33-52

[9] Holloway, J. C. (2014). Marketing for tourism. Harlow, England: Pearson Education Ltd.

[10] Hyland, K. (2005). Metadiscourse: Exploring Interaction in Writing. Continuum.

[11] Hyland, K. 1998,Persuasion and context: The pragmatics of academic metadiscourse. Journal of Pragmatics 30, pp. 437455

[12] Khadohi, B. 1 (2009). Language and the Internet: A Study of Metadiscourse in Corporate Websites on the Nairobi Stock Exchange ( Masters Thesis, Maseno University).

[13] Kress, G., \& van Leeuwen, T. (1996 \& 2006). Reading images: The grammar of visual design. London, Routledge.

[14] Kress, G. (2010) Multimodality: A social semiotic approach to contemporary communication, Routledge

[15] Kumpf, E. (2000). Visual metadiscourse: designing the considerate text. Technical Communication Quarterly, 9 (4), 401-424.

[16] Lippert, A. (2017) What is a poster? Poster House

[17] Ly, T.H \& Jung, C.K. (2015). Multimodal Discourse: A Visual Design of Two Advertising Images. International Journal of Contents, Vol.11, No.2.
[18] Michael, L. (2008). Nanti evidential pratice: Language, knowledge, and social action in an

[19] Amazonian society. PhD dissertation, University of Texas at Austin.

[20] O'Halloran, K. L. (2004). The dynamics of visual semiosis in film. In Kay Lynette O'Halloran (ed.), Multimodal discourse analysis, 109-130. Continuum

[21] Oyebode. O. \& Unuabonah F.0 (2013). Coping with HIV/AIDS: A Multimodal Discourse Analysis of Selected HIV/AIDs Posters in south-western Nigeria. 24(6) Discourse and Society. 810-827

[22] Shorten, A and Smith,J (2017) Mixed methods research: expanding the evidence base. Evidence-based nursing, 20 (3). pp. 74-75.

[23] Scott, M. (1997). Wordsmith Tools Version 4. Oxford University Press.

[24] Vande Kopple, W. J. (1985). Some Exploratory Discourse on Metadiscourse. College Composition and Communication. 36(1). 82-93.

[25] Yueqin G. \& Li,, R. (2020). Visual Grammar in practice: analyzing discourses with words and images of COVID 19 pandemic in China. International Journal of Social Science and Education Research; 3(9):10-18, 2020. 